\title{
InNOVATIVE ASSESSMENT OF CEAB GRADUATE ATTRIBUTES IN Large Class: LAW and Ethics in Engineering PraCtice
}

\author{
Said M. Easa, ${ }^{1}$ Marc A. Rosen, ${ }^{2}$ and D. Robert Beaumont ${ }^{3}$ \\ ${ }^{1}$ Director of Quality Assurance, Faculty of Eng., Arch. and Sci., Ryerson University, \\ Email: seasa@ryerson.ca \\ ${ }^{2}$ Professor, Faculty of Eng. and Appl. Sci., University of Ontario Inst. of Technology, Email: m.rosen@uoit.ca \\ ${ }^{3}$ Osler, Hoskin and Harcourt LLP, Email: RBeaumont@osler.com
}

\begin{abstract}
Four CEAB graduate attributes were assessed in a fourth-year common engineering course. The graduate attributes assessed were: professionalism, impact of engineering on society and environment, ethics and equity, and lifelong learning. The course addressed the legal and ethical aspects of engineering practice. The learning objectives were assessed in the midterm and final exams for the entire class (446 students) using multiple choice questions. An innovative method to assess the learning objectives was developed. Each learning objective was divided into a number of knowledge elements or case-study behavioural elements. A question was then developed for each element. The group of questions was used as the basis for establishing scales to measure student performance. Three scales were defined: poor, average, and excellent based on the number of questions the students answered correctly. Based on the assessment results, program improvements related to the learning objectives were identified.
\end{abstract}

Keywords: Accreditation; Direct assessment; Graduate attributes; Multiple-choice questions; Large class.

\section{INTRODUCTION}

The Canadian Engineering Accreditation Board (CEAB) recently introduced an outcome-based criterion for the accreditation of engineering programs. The criterion includes 12 graduate attributes. According to this criterion, each engineering program in Canada must have a system in place for continuously assessing these attributes and using the assessment results to improve the program. Four CEAB graduate attributes were assessed at Ryerson University in the fourth-year common engineering course "Law and Ethics in Engineering Practice." The graduate attributes assessed in the course were professionalism, impact of engineering on society and environment, ethics and equity, and lifelong learning. For these graduate attributes, eight learning objectives were identified and assessed.

The learning objectives (LO) were assessed in the midterm exam (law part) and the final exam (ethics part). The exams include multiple choice questions and the assessment was performed for the entire class (446 students). An innovative method to assess the learning objectives was developed. The graduate attributes were assessed using groups of exam questions. The assessment of this course is part of a plan to assess CEAB graduate attributes in the Faculty of Engineering, Architecture and Science (FEAS) during 2011-2012 academic year [1,2].

The following sections present course information and the proposed assessment concept. The methods used for the applying the concept and the analysis results are then presented, followed by the conclusions.

\section{COURSE INFORMATION}

\subsection{Course Description}

The course addresses the legal and ethical aspects of engineering practice, including the Canadian legal system and business organizations, tort liability, business contract law, intellectual and industrial property, principles of arbitration and alternative dispute resolution, the practice of engineering, occupational health and safety, ethical aspects of engineering practice, ethical dilemmas in project management, sustainable development and ethical behaviour, and globalization and international standards for ethical and social responsibility.

\subsection{Course Learning Objectives}

The four CEAB graduate attributes assessed in this course were [3]:

- Professionalism (Attribute 8): An understanding of the roles and responsibilities of the professional engineer in 
society, especially the primary role of the protection of the public and the public interest.

- Impact of engineering on society and environment (Attribute 9): An ability to analyze social and environmental aspects of engineering activities. Such ability includes an understanding of the interactions that engineering has with the economic, social, health, safety, legal, and cultural aspects of society, the uncertainties in the prediction of such interactions; and the concepts of sustainable design and development and environmental stewardship.

- Ethics and equity (Attribute 10): An ability to apply professional ethics, accountability, and equity.

- Lifelong learning (Attribute 12): An ability to identify and to address their own educational needs in a changing world in ways sufficient to maintain their competence and to allow them to contribute to the advancement of knowledge.

For these graduate attributes, the following learning objectives were identified and assessed (Note: the number in parentheses refers to the attribute number and the letter refers to its dimension, see [2]):

1. Recognizes and understands basic legal principles relating to legal issues that are faced by engineers in their practices (10a).

2. Evaluates competing legal principles and analyzes issues in terms of these legal principles and to either make decisions accordingly or to seek professional legal assistance (10a).

3. Knows regulations governing professional practice, such as the Professional Engineers Act (8c).

4. Considers economic, social, and environmental factors in decisions (9a).

5. Understands the impact of his/her decisions and activities on the environment (9a).

6. Assesses ethical risks and evaluates situations and actions in terms of the professional code of ethics for engineers, with a focus on that for Ontario (10a).

7. Evaluates competing values in decision making, analyzes components of a decision in terms of professional codes of ethics and other ethical guidelines, and makes decisions accordingly (10a).

8. Recognizes the need for ongoing professional development to maintain competence in the field (12a).

\section{PROPOSED METHOD}

In assessing the learning objectives of the $\mathrm{CEAB}$ graduate attributes, it is necessary to define scales to assess student performance. The number of scales varies depending on the type of graduate attribute and the learning objective. Some methods consider three scales (e.g. poor, average, and excellent), while others consider five scales (e.g. poor, below average, average, above average, and excellent). The definition of the scales may be based on rubrics or some numerical values [4]. For large classes, it is often necessary to use multiple choice questions for which traditional methods would not work. To address this issue, a method is proposed here that allows the use of multiple choice questions to define performance scales for a learning objective.

\subsection{Defining Multiple-Choice Question Groups}

The main idea of this method is to define a group of multiple-choice questions associated with a learning objective. The group of questions can be defined in two ways based on: (a) the main elements associated with the learning objective or (b) the interactions among different players in a case study. These methods are briefly described below.

3.1.1 Element-Based Groups. In this method, it is assumed that there are a number of knowledge elements that a student should know to fully understand the learning objective (Fig. 1). The number of these elements may vary from one learning objective to another and among different assessors. A question is then developed for each of these elements. The performance scale is then defined based on the number of questions in the group that the student correctly answers.

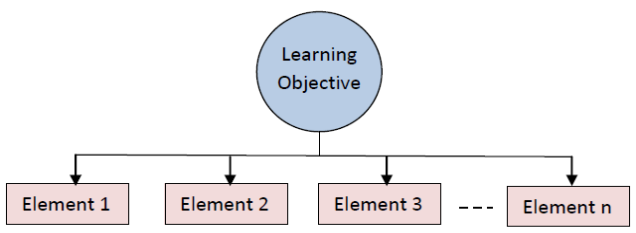

Fig. 1. Defining learning objective by knowledge elements

3.1.2 Behaviour-Based Groups. In this method, a case study that involves a number of players (individual and/or organizations) is developed. The players in the case study have numerous legal and ethical interactions (Fig. 2). A group of questions related to the behavior of the players is then developed to test student understanding of the underlying principles. Similar to the previous method, the performance scale is defined based on the number of questions in the group that the student correctly answers.

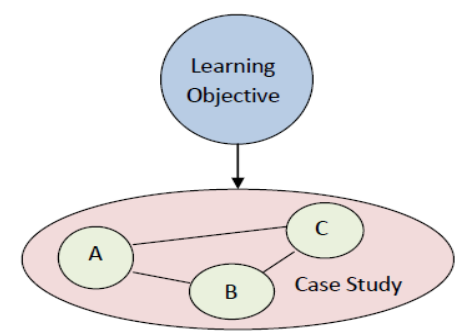

Fig. 2. Defining learning objective by case-study behavioural elements 


\subsection{Defining Performance Scales}

For each learning objective, a group of 3-7 questions was designed to address the important elements or the case study related to each learning objective. For simplicity, a three-scale system is implemented here (poor, average, and excellent). Students' answers were then classified into the three scales based on the number of questions they answered correctly. For example, for the seven-question group, the performance scales are defined as follows:

- Poor (P): Student correctly answers 3 questions or less

- Average (A): Student correctly answers 4 or 5 questions

- Excellent (E): Student correctly answers 6 or 7 questions

Table 1 shows the number of correctly answered questions for each performance scale, for various numbers of questions in the group that is adopted in this study.

Table 1: Definition of number of questions correctly answered for various performance scales

\begin{tabular}{cccc}
\hline \multirow{2}{*}{$\begin{array}{c}\text { No. of } \\
\text { Questions }\end{array}$} & \multicolumn{3}{c}{$\begin{array}{c}\text { No. of Questions Correctly Answered } \\
\text { for Performance Scale }\end{array}$} \\
\cline { 2 - 4 } in Group, n & Poor & Average & Excellent \\
\hline 3 & 1 or less & 2 & 3 \\
4 & 1 or less & 2 or 3 & 4 \\
5 & 2 or less & 3 & 4 or 5 \\
6 & 2 or less & 3 or 4 & 5 or 6 \\
7 & 3 or less & 4 or 5 & 6 or 7 \\
\hline
\end{tabular}

\section{ILLUSTRATION}

The eight learning objectives are assessed in the midterm and final exams using multiple choice questions. The exams involved about 60 and 80 questions, respectively. The question groups for assessing the learning objectives were subsets of the total exam questions. As previously mentioned, the assessment was performed for the entire class using an innovative method that aids the collection and analysis of the attributes data.

The proposed method of establishing question groups is illustrated in this section using four selected learning objectives $(1,3,4$, and 7$)$ of the eight assessed in the course. The question groups for these learning objectives are 31-35, 70-75, 12-18, and 49-53, respectively.

\subsection{Elements of Learning Objective 1}

This learning objective is related to student knowledge about a typical contract administration responsibility required of an engineer through a simple case study. Many engineers play an important role in the administration of equipment supply contracts and construction contracts and in doing so must have a clear understanding as to what is required of the parties in each applicable contract. This learning objective tests knowledge related to one of the most significant contract administrative responsibilities that an engineer is regularly called upon to perform. The case study follows:

"An owner contracted with a design-builder for the design and construction of a building. The contract price for design and construction work was \$9,500,000. When the design-builder determined that it had achieved substantial performance it advised the Owner's consultant, who inspected the work and determined that: (a) the work was ready for the purpose intended and (b) the rectification of known defects and the completion of incomplete items would cost \$112,000."

Five multiple choice questions are then developed as follows (possible answers are not given here):

- What is the Owner's consultant's responsibility if it is the contract administrator of the design-build agreement?

- What is the dollar threshold below which the value of defects to be remedied or incomplete work to be performed must fall before Substantial Performance is achieved?

- Has the design-builder achieved Substantial Performance of its contract?

- When can the Owner release the basic holdback to the design-builder?

- When can the Owner release the finishing holdback?

\subsection{Elements of Learning Objective 3}

This learning objective is related to student knowledge about the regulations governing professional practice. Knowledge of professional engineering regulations is necessary for graduating students both in the short and long terms. In the short term, knowledge about license eligibility requirements, professional exam, and required experience is important. In the long term, the engineer should know disciplinary procedures and behaviours, and rendering services outside of his/her employment [6].

The elements of this learning objective, for which six questions are developed, are shown in Fig. 3. These elements represent knowledge areas the instructor wants the students to learn for this learning objective. They are:

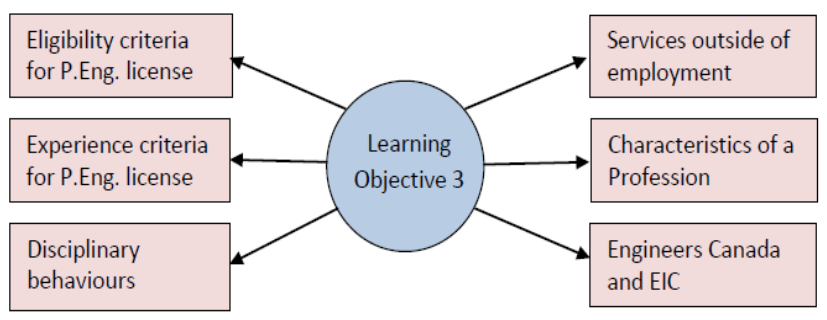

Fig. 3. Elements of Learning Objective 3 (knowledge of regulations of professional practice) 
- Characteristics of a Profession.

- Eligibility criteria for professional engineering license.

- Experience criteria for professional engineering license.

- Services outside of employment.

- Disciplinary behaviours.

- Engineers Canada and Engineering Institute of Canada.

\subsection{Elements of Learning Objective 4}

This learning objective is related to Social responsibility which is the obligation of an organization or individual to act to benefit society at large. The objective of social responsibility is to contribute to sustainable development. International standard for social responsibility has been recently developed and provides guidance to organizations regarding its underlying principles, core subjects and issues, and ways for integrating it into the organization [5].

The learning objective aims at developing student's knowledge about ethical and socially responsible behavior. This knowledge will enable an engineer to identify and accept responsibility for the impacts of his/her decisions and activities on society and the environment. The learning objective has six elements for which seven questions are developed. The elements are:

- Ethical and social responsibility

- Benefits of implementing social responsibility

- What is a Sustainability Report?

- Being socially responsible

- Sustainable development

- Community involvement and development

\subsection{Elements of Learning Objective 7}

Making ethical decisions requires the ability to make distinctions between competing choices. This learning objective involves the ability to evaluate competing values in decision making and to analyze the components of a decision in terms of professional codes of ethics and other ethical guidelines and resources, in order to make ethical decisions accordingly and in an informed manner. This learning objective is illustrated in Fig. 4, where three broad elements of the learning objectives are shown. Five questions are developed for this group based on the three broad elements shown in the figure.

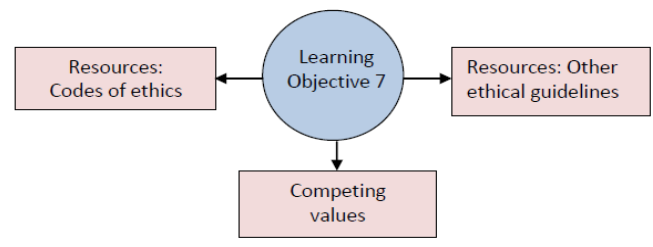

Fig. 4. Elements of Learning Objective 7 (analysis of decision components)

\section{RESULTS AND DISCUSSION}

Before presenting the results of the eight learning objectives assessed, it is useful to briefly describe how the data are processed and analyzed.

\subsection{Data Processing}

The multiple choice exams were administered through scantron sheets in which students mark one choice for each multiple choice questions. The scantron sheets are then processed through the media printing centre and a report presenting the results of answering the questions along with statistics is emailed to the instructor. The report provides the number of total exam questions each student answers correctly. The report presents for each student a row whose columns are the exam question numbers. In this row, the questions answered incorrectly are indicated in the respective cell by the choice number that the student selected, and for those answered correctly the cell is left blank. This format makes it easy to see the questions in the group correctly answered.

The row information for each student is then used to determine the number of questions correctly answered for each group of questions related to a learning objective. Clearly, to simplify collecting the data from the results report, the questions of each group are made consecutive in the exams. For each question group, the number of correctly answered questions for each student is recorded in a spreadsheet. The spreadsheet is then used to analyze the data according to the performance scales of Table 1.

\subsection{Results of Learning Objectives}

The performance results are presented in Figs. 5 and 6 which correspond to the law and ethics parts of the course, respectively. The learning objectives associated with the question groups are shown in Table 2. For all learning objectives, a target (T) and a threshold (TH) of $80 \%$ and $95 \%$ are selected. Student performance refers to the sum of the average and excellent percentages $(\mathrm{A}+\mathrm{E})$. The performance of learning objectives 4-6 exceeded the target and therefore the results are not presented here.

5.2.1. Learning Objectives 1 and 2. For learning objective 2, students performed well as shown in Fig 5 . For learning objective 1 (basic legal principles), the related questions appear not to have been very well answered. However, the results are not that surprising. These results represent one half of the class and the results for the other half have a very similar distribution. Although the questions reflect a very typical contract administrative responsibility required of an engineer, it is 
Table 2: Question groups for learning objectives

\begin{tabular}{cc}
\hline $\begin{array}{c}\text { Learning } \\
\text { Objective No. }\end{array}$ & $\begin{array}{c}\text { Question } \\
\text { Group }\end{array}$ \\
\hline 1 & $31-35$ \\
2 & $36-38$ \\
3 & $70-75$ \\
4 & $12-18$ \\
5 & $19-24$ \\
6 & $32-37$ \\
7 & $49-53$ \\
8 & $82-84$ \\
\hline
\end{tabular}

a responsibility with which many senior practitioners have challenges.

Notwithstanding this reality, the results do indicate that improvements are necessary to enhance the students' understanding of this important responsibility. More time and more examples and case studies could be introduced to help convey the principles addressed in this series of questions. Although this series of questions deal with the Construction Lien Act and many students may view this legislation as something that will not be applicable to them, it does end up having very broad application. As a result, it is evident that more emphasis needs to be placed on conveying the significance of understanding issues that on their face may not appear to be of relevance. This may be accomplished using more real life examples.

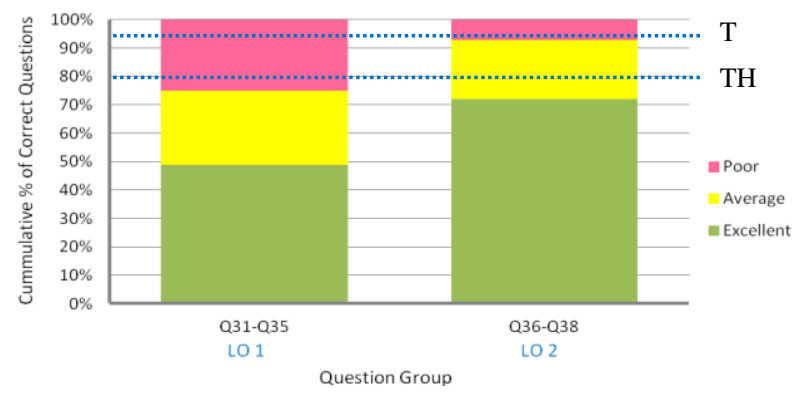

Fig. 5. Performance results for Learning Objectives 1 and 2 (Law Part)

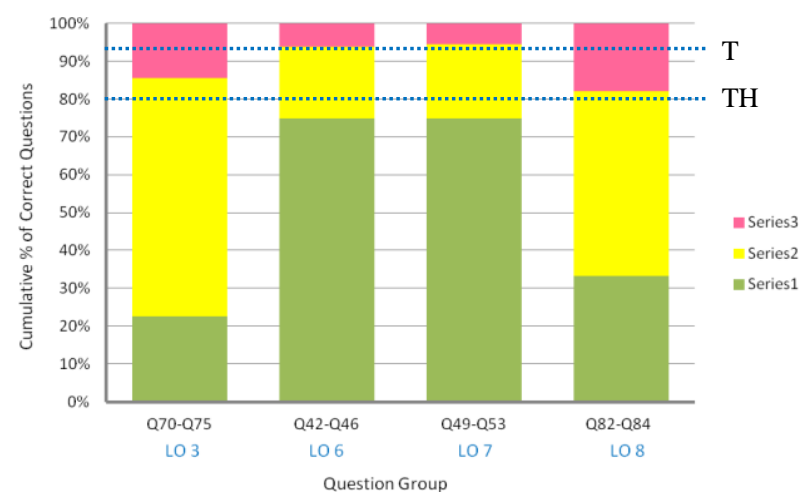

Fig. 6. Performance results for learning objectives 3 , 6, 7, and 8 (Ethics Part)
5.2.2. Results of Learning Objective 3 and 8. For learning objective 3 (regulations of the profession), the student performance is $86 \%$ which lies above the threshold, but below the target. It is also observed that the percentage of students in the average scale is very large. Most of these students answered 3 questions correctly out of the six questions in this group. After reviewing the questions in this group, it was found that one question had two possible correct answers. Although students were asked to give the best answer to each question, the two possible answers for this question were not very far apart. This question will be revised and made crisp. In addition, to improve this learning objective as a whole, a related quiz will be implemented and discussed using clickers.

For learning objective 8 (lifelong learning), the results show a performance of $81 \%$ which exceeds the threshold. However the percentage of students in the average scale is large. These results are mainly due to the fact that this group had three questions. Most students answered two questions correctly and their performance is considered average. The few questions used reflect the challenge that exists in assessing lifelong learning. More questions will be added to this question group in the future.

5.2.3 Results of Learning Objectives 6 and 7. The results these learning objectives are similar and only the results for the latter are discussed here. For learning objective 7 (competing values in decision making), its questions were relatively well answered by the students, with $95 \%$ obtaining average plus excellent grades. Of the $95 \%$ of students meeting the target value, most $(75 \%)$ answered in the excellent range, while $20 \%$ received the average ranging. The distribution of answers followed a typical distribution, with most students answering 4 of the 5 questions related to this learning objective correctly. Very few students were unable to answer 2 of the 5 questions correctly.

Student performance on this learning objective, being strong, did not suggest significant changes to be necessary to how the learning objective is taught. Nonetheless, to improve student mastery of this learning objective, some improvements are possible and worth contemplating. First, more case studies could be introduced to allow students to better understand how the material taught on the learning objective, which can seem quite theoretical, relates to real situations where decision making on ethical matters is required. This improvement could assist in allowing students who learn better by example to grasp the essential aspects of the learning objective.

Second, it can be better emphasized that the informed decision making envisioned through this learning objective involves three distinct phases: acquire and use appropriate resources, analyze all components of the decision making process, and reach an informed and 
appropriate decision. This improvement may help avoid the confusion that some students seem to experience in distinguishing different aspects of the learning objective.

\section{CONCLUSIONS}

This paper has presented an innovative method for assessing $\mathrm{CEAB}$ graduate attributes in large classes. The method assumes that a learning objective can be broken down into elements representing knowledge topics the student should know. In addition, the method can be applied to case studies. The case study is designed to involve players with interactions involving the principles related to the learning objective.

The method performed well in assessing four graduate attributes in the common engineering course Law and Ethics in Engineering Practice. The method can be used for assessing other attributes as well. Some important aspects of the proposed method that require attention is the number of questions in the group, where the use of few or even number of questions in the group should be avoided. Odd number of questions in the group provides a better representation of the Average scale of student performance. The proposed method can be further refined to include additional features.

\section{Acknowledgements}

The authors are grateful to Salma Tawfiq for her assistance in the analysis of the assessment information. The authors also acknowledge the contributions of the following individuals: Andrew Wong and Rocco Sebastiano (Law part) and Robert White (Ethics part). The assessment conducted in this course is part of a graduate attribute assessment process held in the Faculty of Engineering, Architecture and Science at Ryerson University during 2011-2012.

\section{References}

[1] Said M. Easa, One-year outcome-based assessment at Ryerson University: Lessons and best practices. Proc., Canadian Engineering Education Association (CEEA12) Conf., 2012 (Paper 63).

[2] Ryerson University. Assessment of CEAB Graduate Attributes: Plan and Results (2010-2011). Faculty of Engineering, Architecture and Science, Toronto, Ontario (Note: there are eight reports, one for each of the engineering programs).

[3] Canadian Engineering Accreditation Board. Accreditation Criteria and Procedures. CEAB, Ottawa, Ontario, 2010, 87 pp. \{ISSN 1708-8054\}.

[4] Joni Spurlin, Sara A. Rajala, and Jerome P. Lavelle (eds.), Designing better engineering education through assessment. Stylus Publishing, Sterling, Virginia, 2008, 360 pp. \{ISBN 978-1-37932-212-3\}

[5] International Organization for Standardization. Guidance on social responsibility, ISO26000, First Edition, 2010, Switzerland (www.iso.org).

[6] Gordon C. Andrews, Canadian Professional Engineering and Geoscience: Practice and Ethics, Nelson Education2010 \{ISBN : 0-17-644134-4\}. 